\title{
PENERAPAN VIEWBOARD PENILAIAN PEMBIMBING PADA PESSTA+ S2 BERBASIS YII FRAMEWORK SEBAGAI MEDIA INFORMASI DI PERGURUAN TINGGI
}

\author{
Nurlaila Suci Rahayu Rais*1, Yulianto $^{2}$, Egi Wijatriana Bachri ${ }^{3}$ \\ ${ }^{1}$ Program Studi Manajemen Informatika Fakultas Sains dan Teknologi Universitas Raharja \\ ${ }^{2,3}$ Program Studi Sistem Informasi Fakultas Sains dan Teknologi Universitas Raharja \\ Email: *11 nurlaila@ raharja.info, ${ }^{2}$ yulianto@ raharja.info, ${ }^{3}$ wijatriana@ raharja.info
}

\begin{abstract}
Abstrak
Teknologi informasi dalam bidang komunikasi memiliki peran yang sangat penting, karena dengan adanya informasi yang mendukung akan tercipta komunikasi yang baik dan efektif. Di era pesatnya perkembangan teknologi ini, sangat dibutuhkan sebuah fitur yang dapat memudahkan dalam mendapatkan sebuah informasi dengan cepat. Viewboard merupakan sebuah fitur yang dapat menampilkan informasi dengan tampilan yang menarik berupa grafik. Di Universitas Raharja terdapat sebuah sistem yang dapat memberikan kemudahan bagi mahasiswa secara online dan mandiri sebagai media untuk memenuhi poin penilaian sidang thesis yaitu PESSTA+ (Penilaian Sidang Thesis Plus). Pada PESSTA+ terdapat sebuah menu untuk Dosen Pembimbing dalam melakukan submit Penilaian Pembimbing mahasiswa yang menjadi bimbingannya masing-masing. Adapun metode yang digunakan pada penelitian ini yaitu: Identifikasi Kebutuhan, perancangan, Perancangan Prototype dan juga Review. Oleh karena itu, peneliti berharap dengan dibuatnya sebuah fitur Viewboard pada Penilaian Pembimbing akan dapat menyajikan sebuah informasi yang lebih informatif dan juga akurat kepada para user PESSTA+.
\end{abstract}

Kata Kunci - PESSTA+ , Penilaian Pembimbing, Viewboard

\begin{abstract}
Information technology in the field of communication has a very important role, since the information that supports will create good and effective communication. In this era of rapid development of technology, it is needed a feature that can facilitate getting information quickly. Viewboard is a feature that can display information with an attractive appearance in the form of graphs. At Raharja University, there is a system that can provide convenience for students online and independently as a medium to fulfill the thesis trial evaluation points of PESSTA + (Session Thesis Plus Assessment). At PESSTA + there is a menu for Lecturers in submitting their Valuation Counselors to each student's guidance. The methods used in this study is identification of needs, designing, drafting prototype and also Review. Finally, the researcher hopes that by creating a Viewboard feature in the assessment counselor will be able to present a more informative and accurate information to PESSTA + users.
\end{abstract}

Keywords-PESSTA+, Counselor's Assessment, Viewboard

\section{PENDAHULUAN}

Pada Perguruan Tinggi Raharja sudah tersedianya menu Penilaian Pembimbing yang dibuat untuk memudahkan Dosen Pembimbing dalam melakukan submit nilai untuk mahasiswa 
bimbingan nya masing-masing. Tetapi user PESSTA+ masih belum mendapatkan informasi secara akurat tentang Dosen Pembimbing yang sudah Input Penilaian maupun yang belum Input.

PESSTA+ (Penilaian Sidang Thesis Akhir) merupakan sebuah sistem validasi Penilaian Objektif Sidang yang dapat diakses secara mandiri dan online, sehingga Mahasiswa dapat melakukan submit dimanapun dan kapanpun. Yang ditujukan untuk mempermudah mahasiswa dalam memenuhi 10 point Penilaian Objektif pada saat Sidang Thesis.

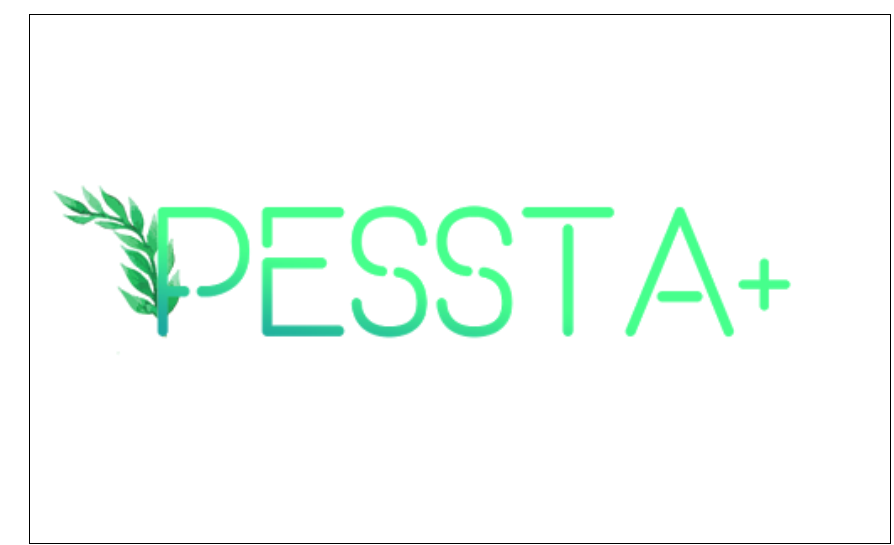

Gambar 1. Logo PESSTA+ pesstaplus.raharja.ac.id

Viewboard merupakan sebuah fitur yang dapat menampilkan informasi dalam bentuk grafik yang sangat penting bagi Pemimpin sebuah Institusi, maupun Admin. Viewboard juga dapat memonitoring suatu sistem agar dapat sesuai dengan tujuan dan visi misi yang telah ditetapkan.

Pada saat ini sudah banyak penggunaan Viewboard pada suatu sistem maupun suatu website. Maka dari itu, peneliti ingin menerapkan sebuah fitur Viewboard Penilaian Pembimbing pada website PESSTA+ agar dapat memonitoring dan memantau siapa saja yang sudah melakukan input nilai maupun yang belum melakukan input nilai. Viewboard ini dapat memudahkan user PESSTA+ dalam mendapatkan informasi mengenai Penilaian Pembimbing.

\section{METODE PENELITIAN}

Dalam sebuah penulisan penelitian dibutuhkan metode penelitian yang dapat berguna untuk mencapai tujuan dan juga mendapatkan informasi yang lebih terpercaya yang dibutuhkan oleh penulis untuk melakukan beberapa tahapan dalam penelitian. Dibawah ini merupakan rancangan metode penelitian yang digunakan:

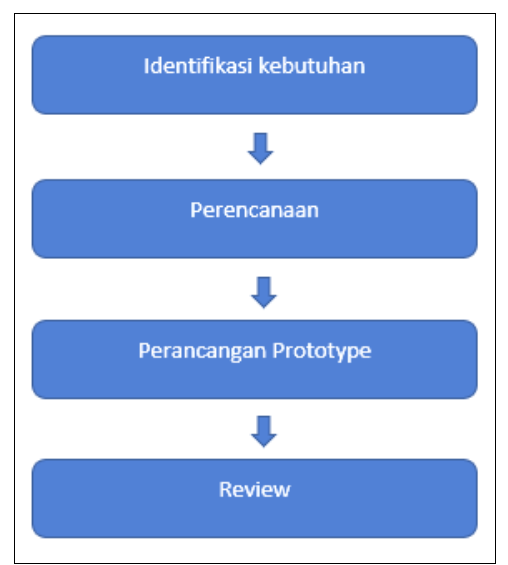

Gambar 2. Rancangan Metode Penelitian 
Terdapat 4 rancangan metode penelitian yang harus diperhatikan dalam penelitian ini, yaitu melakukan identifikasi kebutuhan untuk mendapatkan gambaran mengenai penyajian informasi pada viewboard yang akan dirancang, selanjutnya melakukan perencanaan untuk menganalisa data yang sudah diperoleh dari hasil identifikasi kebutuhan, langkah berikutnya yaitu perancangan prototype agar dapat melihat kesesuaian antara kebutuhan user dengan sistem yang akan direncanakan, dan yang terakhir adalah review dimana tahap terakhir ini untuk melakukan perbaikan pada sistem jika terjadi ketidaksesuaian dengan kebutuhan para user.

Terdapat beberapa literature review yang telah disiapkan untuk mengidentifikasi kesenjangan, menghindari pengulangan pengulangan dan untuk meneruskan penelitian yang sebelumnya telah dilakukan. Berikut beberapa literature review diantaranya:

1. Penelitian yang dilakukan oleh Untung Rahardja, Indri Handayani dan Randy Wijaya pada Technomedia Journal (TMJ) Vol 2 No 2 tahun 2018 yang berjudul Penerapan Viewboard Technomedia Journal menggunakan sistem iLearning Journal Center pada Perguruan Tinggi". Dalam penelitian nya mereka membahas tentang penerapan viewboard TMJ sebagai tempat pelayanan informasi dari data-data yang sudah ada dan sudah terkait dengan penulisan karya ilmiah atau jurnal lainnya, sehingga akan menampilkan informasi yang lebih valid dan memudahkan admin untuk mengelola data tersebut.

2. Penelitian yang dilakukan oleh Kenneth C. Gardner dkk (2016) yang berjudul " Analytic Dashboard with user interface for producing a single chart statistical correlation from source and target charts during a load test. Mereka membahas tentang penyediaan dashboard analitik dengan antarmuka pengguna grafis (GUI) yang menampilkan hasil agregat streaming secara real-time dari tes beban yang dilakukan pada situs web target. Responsif terhadap input pengguna pada GUI, input yang terdiri dari pemilihan bagan sumber dan bagan target, bagan tunggal secara otomatis dihasilkan yang mewakili kombinasi atau korelasi statistik dari bagan sumber dan target.

3. Penelitian yang dilakukan oleh Untung Rahardja, Indri Handayani dan Lilis Setiani pada Cogito Vol 3 No 1 tahun 2017 yang berjudul “ Viewboard Sebagai Laporan Jumlah Keseluruhan Artikel Pada iLearning Raharja Ask and News". Dalam penelitian nya membahas tentang Viewboard yang dapat dijadikan sebagai sarana untuk memonitoring kerja, mengevaluasi proses dan memberikan solusi bagi proses yang sedang berjalan dan diharapkan penerapannya pada iRAN dapat memberikan informasi mengenai kinerja dari official site iRAN.

4. Penelitian yang dilakukan oleh Dini Nurmalasari, Retro Tri Wahyuni dan Yusmar Palapa pada JNTETI (UGM) Vol 4 No 3 tahun 2015 yang berjudul "Informational Dashboard untuk Monitoring Sistem Drainase secara Real-Time". Mereka membahas tentang Aplikasi monitoring berbasis web yang didukung oleh informational dashboard mampu memberikan data dan informasi mengenai kondisi drainase secara efektif dan efisien. Sistem monitoring juga dilengkapi dengan visualisasi dalam bentuk peta, sehingga pengguna dapat secara langsung mengetahui kondisi terkini setiap stasiun pemantau melalui visualisasi dua

5. Penelitian yang dilakukan oleh Indri Handayani, Erick Febriyanto dan Kevin Rama pada Technomedia Journal (TMJ) Vol 2 No 2 tahun 2018 yang berjudul " Penerapan Viewboard Sebagai Media Informasi Sidang Skripsi pada PESSTA+ di Perguruan Tinggi”. Dalam penelitian nya membahas tentang Penerapan viewboard pada PESSTA+ yang dapat memberikan solusi, mengevaluasi proses dan memonitoring kinerja proses yang sedang berjalan. dengan merancang sebuah viewboard, diharapkan dapat memberikan gambaran informasi mengenai kegiatan sidang skripsi / Tugas Akhir dari PESSTA+.

Dapat disimpulkan dari 5 (lima) Literature Review diatas bahwa permasalahan tentang viewboard sangat memiliki pengaruh yang besar didalam suatu sistem untuk menampilkan sebuah informasi yang dapat memudahkan pembaca dalam mendapatkan sebuah informasi. 


\section{HASIL DAN PEMBAHASAN}

\section{Analisis Permasalahan}

Dengan semakin berkembangnya kemajuan teknologi semakin memudahkan seseorang untuk memperoleh sebuah informasi dari berbagai sumber secara online maupun offline. Semakin banyaknya website pada bidang pendidikan yang memberikan banyak informasi yang dapat diakses kapanpun dan dimanapun. PESSTA+ merupakan sebuah website yang dimiliki oleh Perguruan Tinggi Raharja yang dapat memberikan informasi mengenai Penilaian Objektif, Penilaian Pembimbing maupun Penilaian sidang Mahasiswa Tesis. Pada menu Penilaian Pembimbing terdapat keterbatasan yaitu belum tersedianya viewboard untuk memudahkan user dalam mendapatkan informasi mengenai dosen siapa saja yang sudah melakukan input nilai maupun dosen yang belum melakukan input.

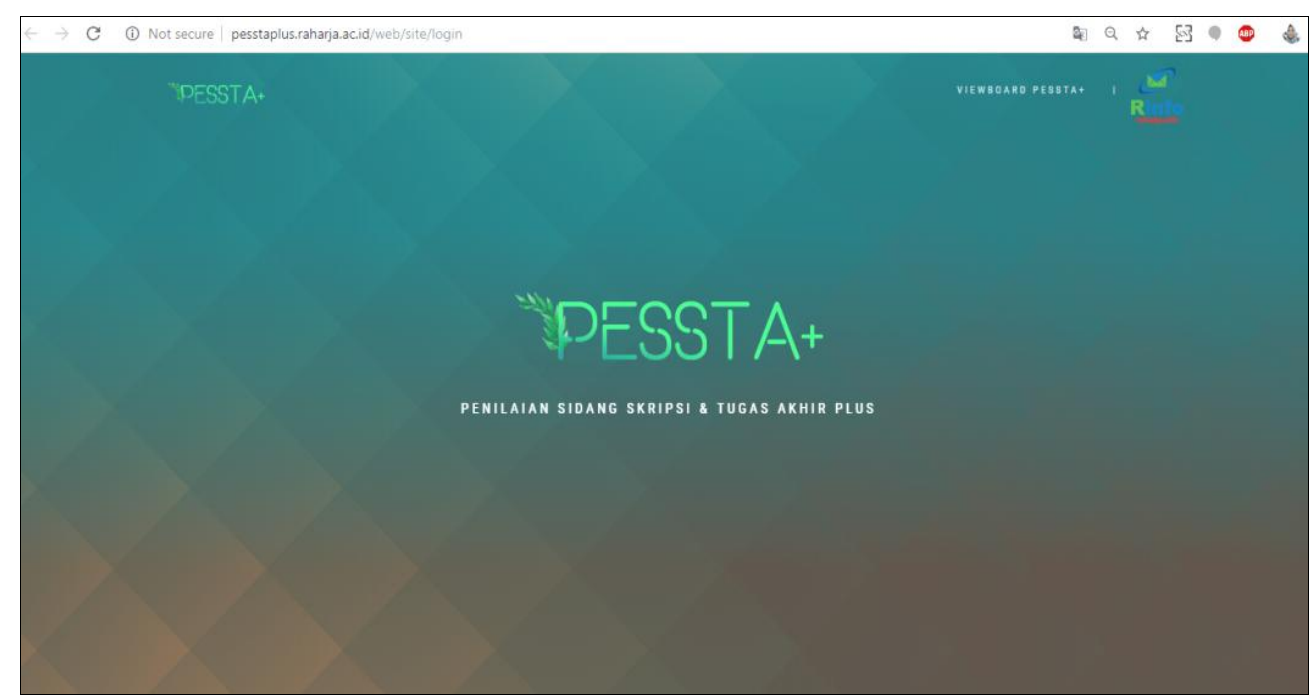

Gambar 3. Halaman Utama PESSTA+

\section{Pemecahan Masalah}

Setelah dilakukan penelitian bahwa masih terdapatnya keterbatasan dalam mendapatkan informasi khususnya pada menu Penilaian Pembimbing. Dimana pimpinan institusi, kajur maupun admin tidak dapat memantau siapa saja dosen yang sudah melakukan input nilai maupun yang belum.

Untuk menyelesaikan permasalahan diatas, maka diperlukan sebuah fitur viewboard yang dapat memudahkan semua user PESSTA+ dalam mendapatkan informasi yang lebih cepat dan juga akurat.

\section{Listing Program}

Dibawah ini merupakan listing program yang terdapat didalam Viewboard Penilaian Pembimbing untuk mahasiswa pascasarjana.

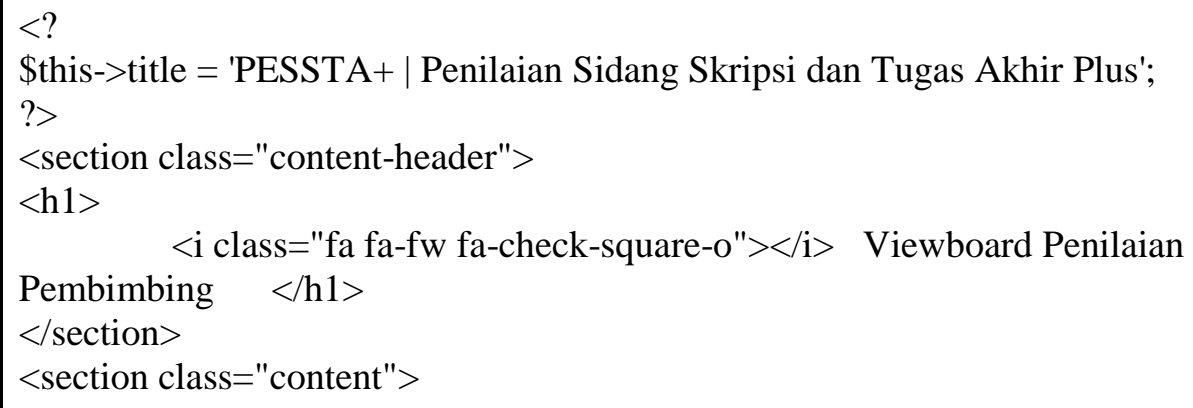




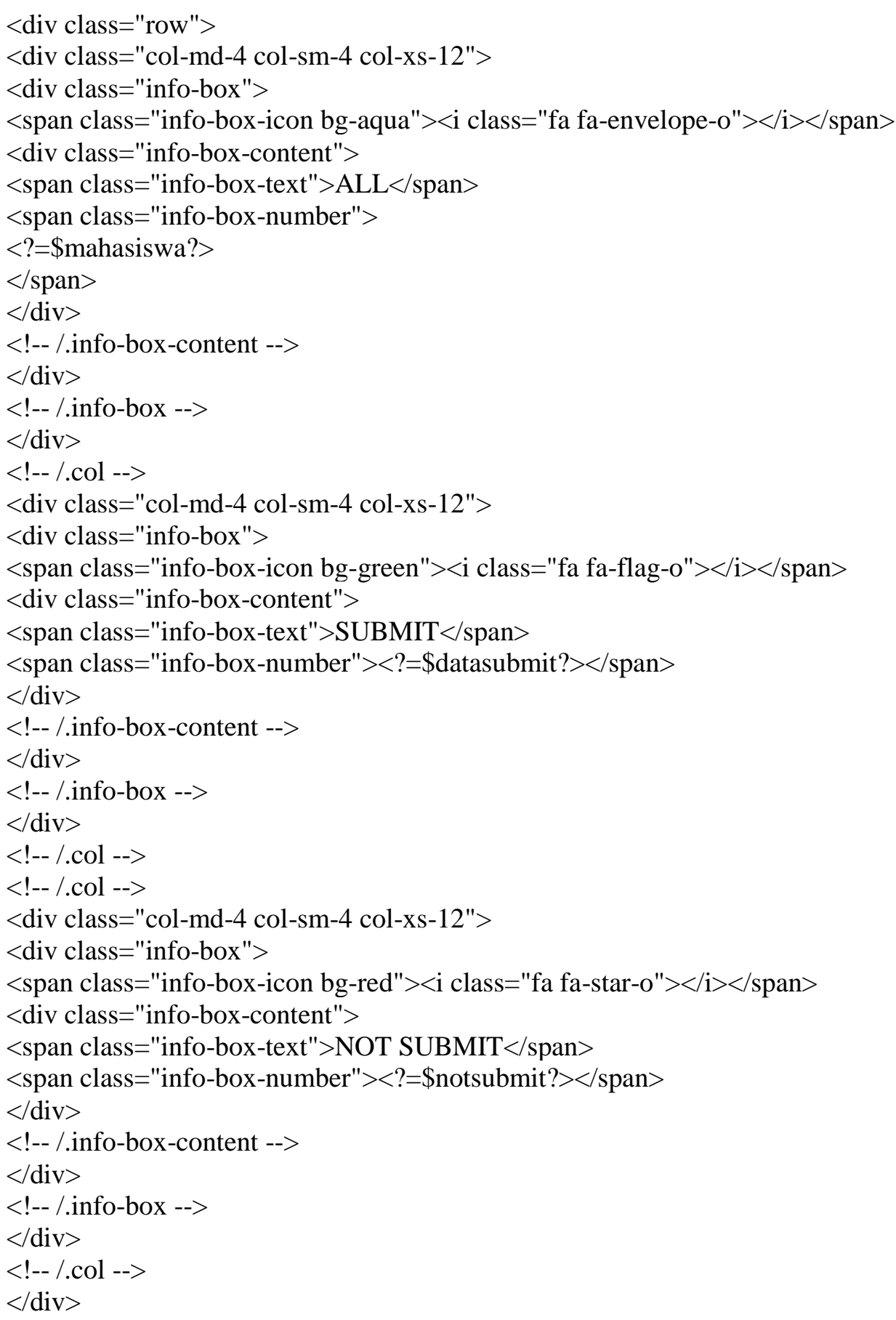

Gambar 4. Script Tampilan Info Box All, Submit, dan Not Submit

Gambar 4 merupakan script tampilan Info Box yang terdiri dari 3 Info Box yaitu Box Data All, Box Submit, dan Box Not Submit. Dimana masing-masing box memiliki data yang berbeda karena Data tersebut sesuai dengan database.

$<$ div class="box box-primary" $>$

$\langle$ div class="box-header with-border" $>$

$<$ h3 class="box-title" $><$ i class="fa fa-fw fa-users" $></$ i $>$ Submit All (Pembimbing 


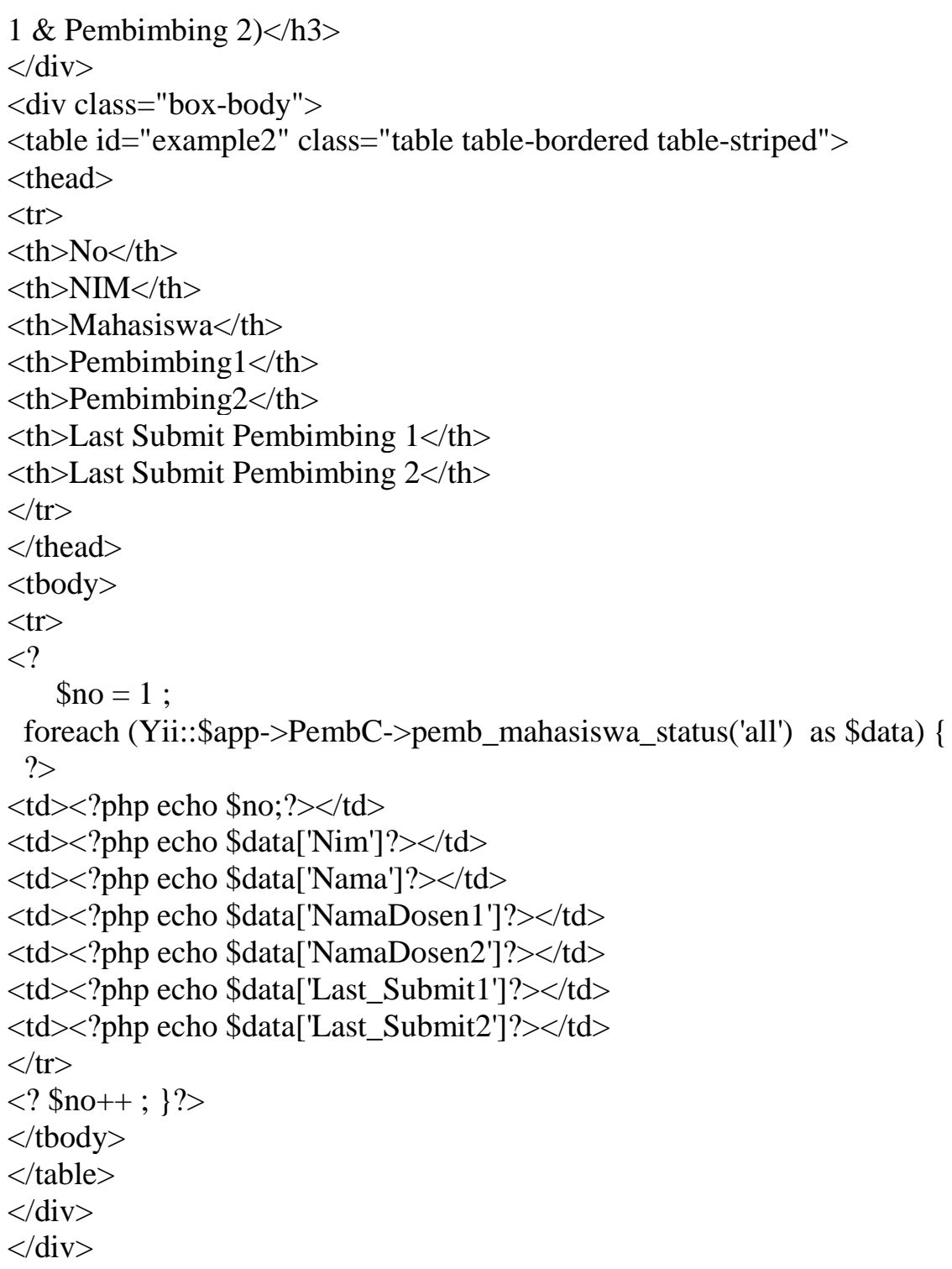

Gambar 5. Script Tampilan Submit All (Pembimbing 1 \& Pembimbing 2)

Gambar 5 merupakan Script Tampilan untuk Table Submit All, dimana table ini berisi data pembimbing 1 dan pembimbing 2 yang sudah melakukan submit nilai .

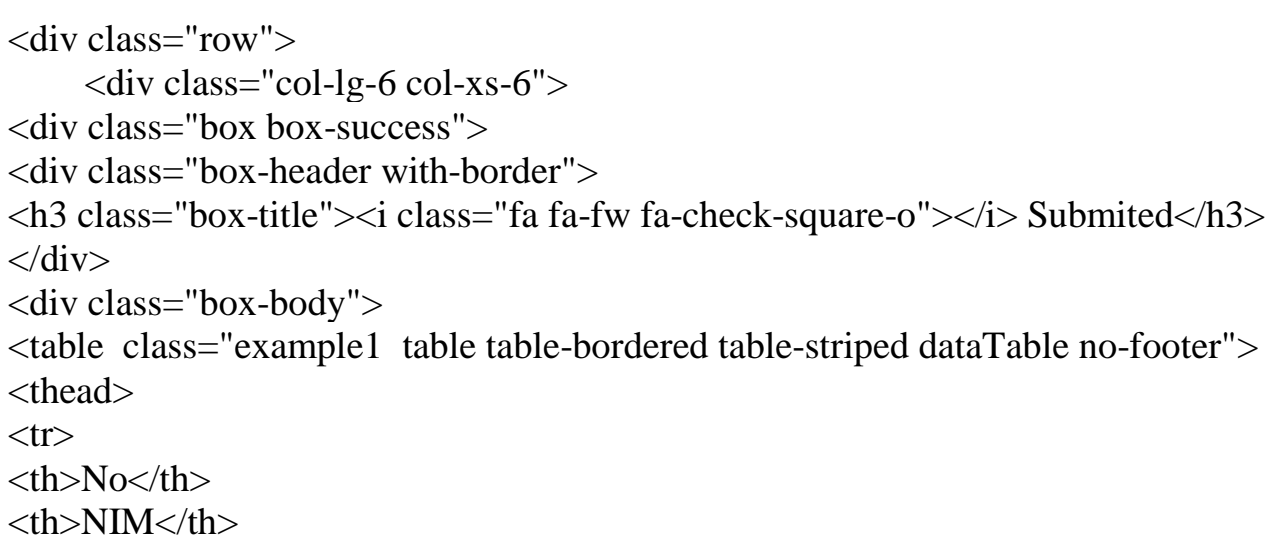




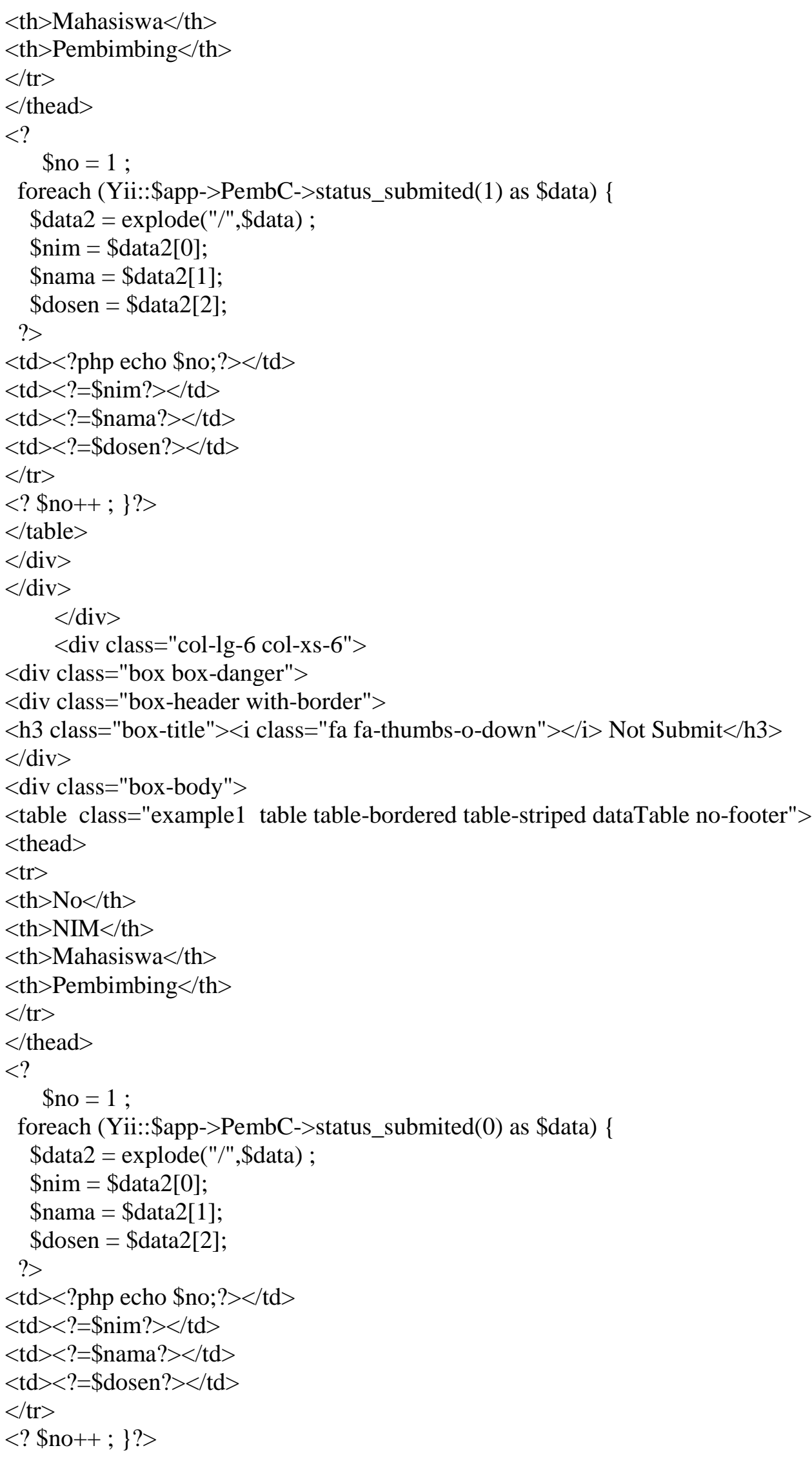




$$
\begin{aligned}
& </ \text { table }> \\
& </ \text { div }> \\
& </ \text { div }> \\
& \quad</ \text { div }> \\
& </ \text { div }>
\end{aligned}
$$

Gambar 6. Script Tampilan Table Submit dan Not Submit

Gambar 6 merupakan Script Tampilan untuk Table Submit dan Table Not Submit yang dimana masing-masing tabel berisi data mahasiswa dan juga pembimbing 1 maupun pembimbing 2 yang sudah melakukan input nilai.

\section{IMPLEMENTASI}

Setelah dibuatnya prototype mengenai Viewboard Penilaian Pembimbing maka selanjutnya akan di implementasi kan kedalam sistem PESSTA+ agar dapat mempermudah user dalam mendapatkan informasi Penilaian Pembimbing.

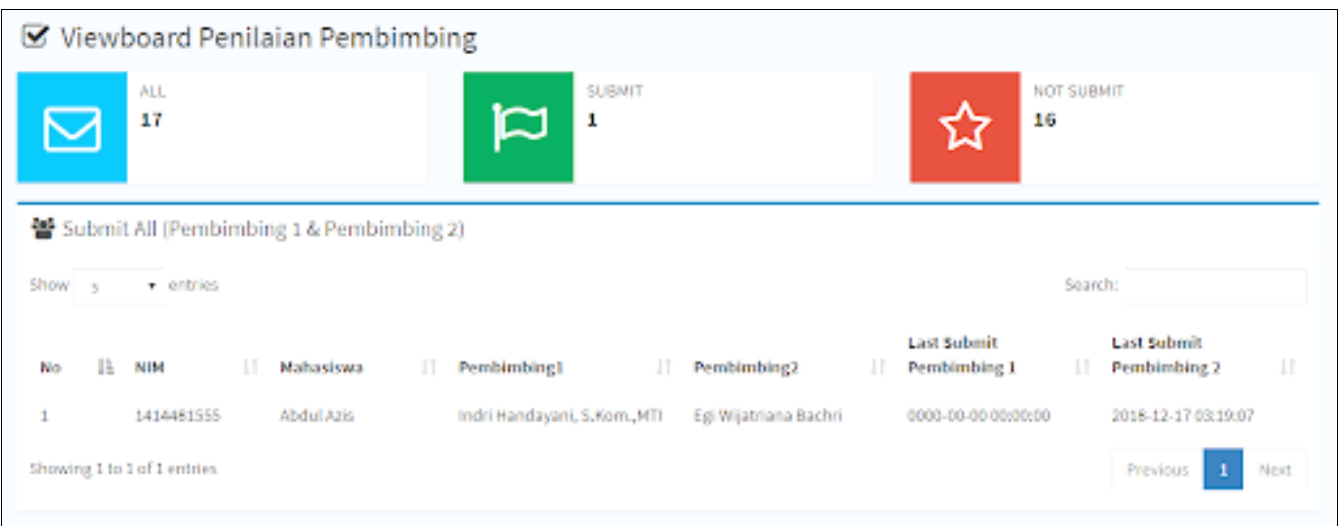

Gambar 7. Tampilan Info Box dan Submit All

Gambar 7 merupakan Tampilan dari Info Box dan juga Table Submit All. Dimana terdapat 3 Info Box seperti All, Submit, dan Not Submit yang masing-masing info box mengambil data dari database Status Submit Dosen. Dan Table Submit All berisi NIM, Nama Mahasiswa, Pembimbing 1, Pembimbing 2 dan juga Last Submit dari kedua pembimbing.

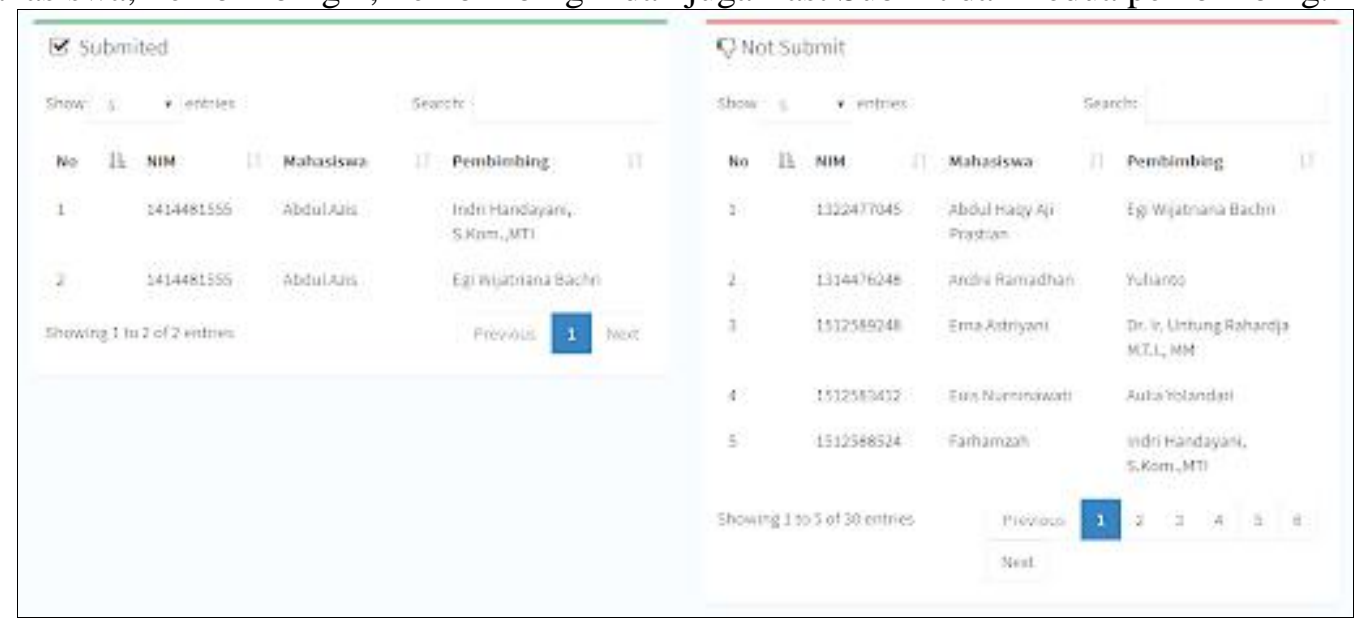

Gambar 8. Tampilan Table Submitted dan Not Submit

Gambar 8 merupakan tampilan untuk Table Submitted dan juga Not Submit. Table Submitted berisi NIM, Nama Mahasiswa dan Pembimbing yang sudah melakukan input Nilai. 
Sedangkan Table Not Submit menampilkan NIM, Nama Mahasiswa dan juga Pembimbing yang belum melakukan input nilai.

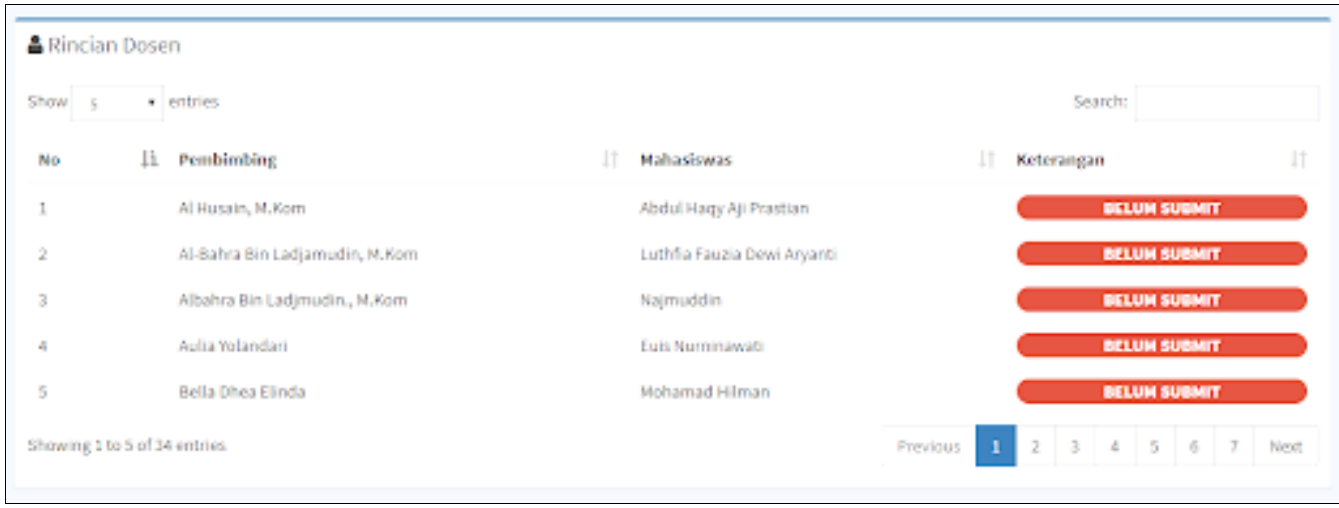

Gambar 9. Tampilan Table Rincian Dosen

Gambar 9 merupakan Tampilan Tabel Rincian Dosen dimana tabel tersebut berisi Nama Pembimbing, Nama Mahasiswa dan juga status submit dari dosen pembimbing tersebut.

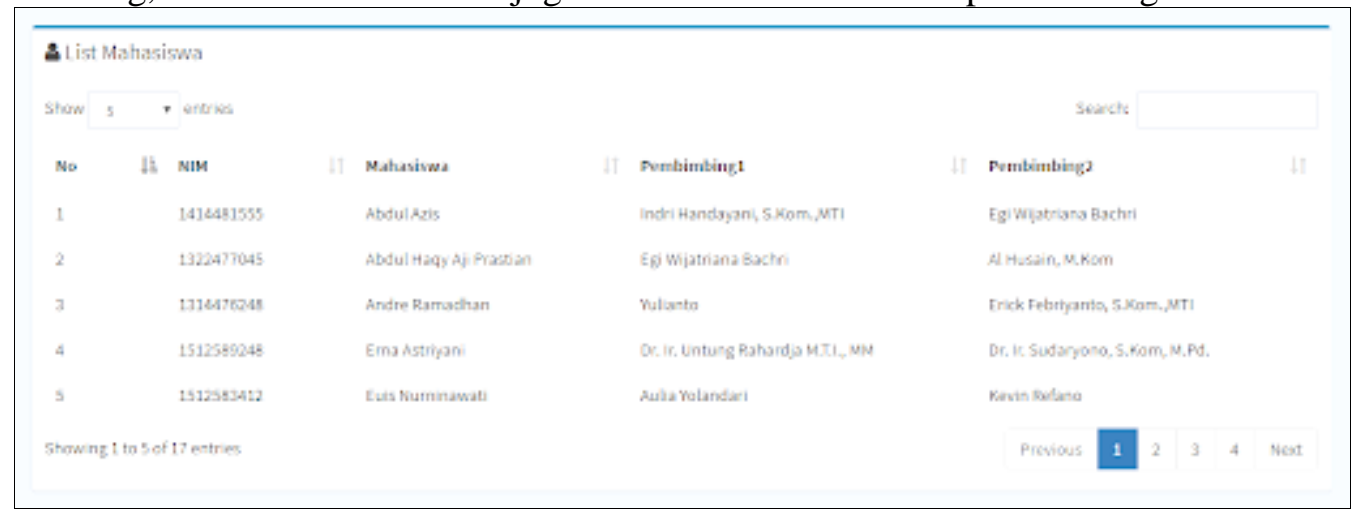

Gambar 10. Tampilan Tabel List Mahasiswa

Gambar 10 merupakan Tampilan Tabel List Mahasiswa dimana tabel diatas berisi NIM, Nama Mahasiswa, Pembimbing 1 dan juga Pembimbing 2.

\section{KESIMPULAN}

Berdasarkan hasil penelitian, dapat disimpulkan bahwa fitur Viewboard pada Penilaian Pembimbing S2 di PESSTA+ sangat membantu Pimpinan, Admin, Kajur, Dosen dan juga Mahasiswa dalam mendapatkan informasi mengenai Penilaian Pembimbing. Pada Viewboard ini akan terlihat tampilan para Dosen yang sudah melakukan input nilai maupun yang belum. Dosen hanya perlu mengakses website PESSTA+ login Rinfo dan memilih menu Viewboard Penilaian Pembimbing

\section{DAFTAR PUSTAKA}

[1] Gardner, K. C., Broda, T., Cosby, K., Esau, D., \& Hemmert, M. (2016). U.S. Patent No. 9,495,473. Washington, DC: U.S. Patent and Trademark Office.

[2] Handayani, I., Febriyanto, E., \& Solichin, K. R. P. (2018). Penerapan Viewboard Sebagai Media Informasi Sidang Skripsi Pada PESSTA+ di Perguruan Tinggi. Technomedia Journal, 2(2), 52-62. 
[3] Rahardja, U., Handayani, I., \& Setiani, L. (2017). Viewboard Sebagai Laporan Jumlah Keseluruhan Artikel Pada iLearning Raharja Ask and News. CogITo Smart Journal, 3(1), 42-55.

[4] Rahardja, U., Handayani, I., \& Wijaya, R. (2018). Penerapan Viewboard Technomedia Journal menggunakan sistem iLearning Journal Center pada Perguruan Tinggi. Technomedia Journal, 2(2), 78-89.

[5] Nurmalasari, D., Wahyuni, R. T., \& Palapa, Y. (2015). Informational Dashboard untuk Monitoring Sistem Drainase secara Real-Time.Jurnal Nasional Teknik Elektro dan Teknologi Informasi (JNTETI), 4(3).

[6] Handayani, I., Febriyanto, E., \& Bachri, E. W. (2018). Aplikasi Stat Counter Sebagai Alat Monitoring Aktivitas Website PESSTA+ Pada Perguruan Tinggi. SISFOTENIKA, 8(2), 188-197.

[7] Febriyanto, E., Handayani, I., \& Bachri, E. W. (2018). Sistem Penilaian Pembimbing pada Pessta+ S2 Berbasis Yii Framework sebagai Media Penginputan Nilai Mahasiswa Pasca Sarjana di Perguruan Tinggi. SATIN-Sains dan Teknologi Informasi, 4(2), 17-23.

[8] http://ijc.ilearning.co/index.php/TMJ/article/view/849/198, diakses 2019.

[9] http://jurnal.stmik-amik riau.ac.id/index.php/satin/article/view/400, diakses 2019.,

[10] https://www.researchgate.net/publication/330549464_Sistem_Penilaian_Pembimbing_pa da_Pessta_S2_Berbasis_Yii_Framework_sebagai_Media_Penginputan_Nilai_Mahasisw a_Pasca_Sarjana_di_Perguruan_Tinggi, diakses 2019. 